\title{
CREANDO EL NACIMIENTO \\ Valores reproductivos en el estado de Chiapas
}

\author{
M. J Jesús Montes* \\ Escuela Universitaria de Enfermeria. Universitat Rovira i Virgili. Tarragona
}

Graciela Freyermuth**

Centro de Investigaciones y Estudios Superiores en Antropologia Social - Suresie. San Cristóbal de las Casas. Chiapas (México)

\section{RESUMEN}

Las características que envuelven a la región de los Altos de Chiapas han favorecido el aislamiento de muchas de sus comunidades indígenas de las que recogemos sus representaciones y prácticas sobre los cuidados a la reproducción. Nos acercamos al contexto físico y las condiciones de vida para poder entender su cosmovisión y para posteriormente exponer las creencias y actividades que se desarrollas en torno al embarazo, parto, puerperio y cuidados al recién nacido. Estas prácticas están cambiando. El contacto con la medicina alopática, está introduciendo nuevos elementos que se mezclan con el saber tradicional.

Palabras clave: enfermeria, antropologia, cultura de los cuidados, enfermeria transcultural.

\section{CREATING THE BIRTH}

\section{Reproductive values in the state of Chiapas}

\section{SUMMARY}

Characteristics that surround to the region of the tops of Chiapas have favored the isolation of many of their indigenous communities of which we gather its representations and practices on the reproduction's cares. We approached to the physical context and the life's conditions to be able to understand its cosmovisión and later we have exposed the beliefs and activities that they have developed around the pregnancy, childbirth, puerperio and new born cares.

\section{INTRODUCCIÓN}

El estado de Chiapas se sitúa al sureste de México formando frontera con Guatemala. Su gran diversidad geográfica y el aislamiento en que se han mantenido algunas de sus comunidades, hace que hoy se conserven representaciones y prácticas reproductivas diferenciadas entre ellas.

En nuestro trabajo nos vamos a referir a la región de los Altos, que es una de las nueve regiones que conforman el estado de Chiapas y por ser este espacio en el que han trabajado las autoras. La información que presentamos está obtenida en la comunicación mantenida con las parteras y que es asumida por la mayoría de la población. Consideramos, además, que en la evolución cultural de los cuidados, las costumbres y prácticas van modificándose e introduciéndose otras nuevas, esto también se ha observado en las comunidades indígenas de los Altos.

Iniciamos nuestro trabajo haciendo un breve recorrido del espacio físico, económico y de población para situarnos en el contexto de la vida indígena ya que, es en ese contexto donde adquieren sentido las creencias y prácticas sobre los cuidados. Posteriormente, iremos exponiendo sus representaciones, hacer y atención que ofrecen respecto al embarazo, parto y recién nacido.

\section{GEOGRAFÍA, RECURSOS Y POBLACIÓN}

Los Altos es una región de montañas escarpadas y con una población mayoritariamente indígena de las etnias tzeltal y tzotzil. Las comunidades se encuentran muy dispersas y formadas por 
núcleos de menos de 500 habitantes, solo el 3\% de ellas, tiene más de 2000 (1). La falta de infraestructura y disponibilidad de servicios básicos, como el agua corriente y drenaje de residuos, es la tónica dominante. La carretera asfaltada no llega a muchos de los municipios indigenas que continúan con caminos en malas condiciones.

El cultivo principal es el maiz y frijol que se utiliza casi en su totalidad para el consumo familiar. Las dificultades del terreno, su escasez y agotamiento, pone a los habitantes de los Altos en condiciones de extrema pobreza y como resultado, se da una importante migración de los hombres.

Los indígenas hablan lenguas autóctonas y el español solo es hablado por los hombres fuera de su comunidad, las mujeres son monolingües. Los índices más altos de analfabetismo del estado se registran en esta región (2).

La casa es una construcción de madera con techo de palma que está siendo sustituido actualmente por chapa. Tiene un único espacio, en él se cocina, se guardan alimentos y pertenencias y se duerme. El grupo doméstico está formado por los padres, los hijos/as solteros y casados con sus respectivas familias. Las nuevas parejas, cuando obtienen los recursos suficientes, formarán un nuevo hogar con residencia virilocal. Los hombres heredan la tierra y será el de más edad quien domine en el grupo. La atención que se presta a la enfermedad estará relacionada con el género y la generación a que se pertenezca y los cuidados en tomo a la salud o la enfermedad, responderán más a intereses colectivos que individuales (3).

\section{REPRESENTACIONES Y PRÁCTICAS EN TORNO A:}

\section{El embarazo}

Las mujeres comienzan su vida reproductiva alrededor de los 15 años, edad en que son dadas en matrimonio. El embarazo es un evento deseado y se considera como un buen indicador de salud, aunque se acepta que pone a la mujer en una situación de vulnerabilidad y riesgo de enfermar y morir. La participación del marido desde el inicio del embarazo es una garantía para que el nacimiento llegue a buen término, los cuidados del esposo evitarán que aparezcan malestares. Esto se explica por el alto indice de violencia hacia las mujeres y su situación de subordinación total respecto a los hombres. "Al hombre le gusta ver a su mujer embarazada" (Freyermuth 1989;8) (4) que las parteras interpretan como un buen signo ya que, si el marido cuida a la mujer, ella trabajará menos y tendrá alimento suficiente y así, "el bebé estará bien y nacerá bien".

Otra forma de proteger el embarazo es "hacer rezo y prender vela". La gestante debe rezar y también el esposo. Si se tienen medios, se hace este encargo a un j'ilol, que rezará y ayunará en tres ocasiones a lo largo de todo el embarazo. Al final de cada ayuno, se mata ritualmente un pollo que será comido por la familia. Esta costumbre asegura carne a la embarazada.

La partera establece contacto con la gestante alrededor del $7 .^{\circ}$ mes o en el momento que ésta le solicite, y su función será la de dar consejos que garanticen la salud; como la alimentación y la disminución de las cargas de trabajo. Al exceso de trabajo se atribuyen las malas posiciones fetales. También "acomodará" al niño asegurando que permanezca en posición cefálica, para ello, realiza un enérgico masaje en el vientre de la madre. Todas las parteras realizan esta tarea ya que el parto de nalgas es considerado un problema.

Se entiende que la mujer embarazada adquiere un brillo especial en la mirada que le da fuerza y es capaz de causar "mal de ojo". Si el producto de su embarazo es un niño, puede ocasionar este mal a una niña y viceversa. Esta fuerza, por el contrario, limita su capacidad si es curandera. Las plantas medicinales recolectadas por ella, pierden sus cualidades curativas (4). 
Las creencias en torno al embarazo es una forma de dar respuesta a fenómenos que están fuera de la comprensión humana y en los que intervienen fuerzas desconocidas. Las complicaciones son atribuidas bien a castigos divinos, o a fenómenos sobrenaturales que se materializan en malos espíritus, o a conductas dañinas tanto de la embarazada como de su marido (1).

El cambio de sexo, también es un riesgo; las parteras pueden predecir el sexo de la criatura pero este puede ser cambiado si la mujer mira con frecuencia la luna o sueña que se encuentra en el agua.

En otras ocasiones, la "criatura sale huyendo" del vientre de la madre y simultáneamente, otra mujer sin signos previos de embarazo, adquiere un embarazo de tres o más meses. Esta situación es atribuida al demonio y se le llama "el embarazo del mono".

También pueden resultar nocivas otras situaciones como mirar el arco iris, o el mal echado por otro cuando hay envidia del embarazo o soñar, ya que puede intervenir el demonio que actúa por la noche. Todo ello pondrá en riesgo el embarazo. Se considera que, el miedo al maltrato del esposo y la tristeza que genera, puede hacer enfermar a la mujer.

Si la mujer fallece durante el embarazo y el feto tiene más de seis meses, es necesario que se extraiga del vientre y se sepulte junto a su madre, ya que sino, será una carga que se asocia al castigo del infierno (3).

\section{El parto}

Cuando el parto está próximo, en el mejor de los casos, y por conceptos tan variados como la distancia, el comportamiento de la mujer y su relación con su familia o la de su marido, o el interés de este, se llamará a la partera que ha visitado a la gestante durante el embarazo, sino, puede ser la madre o la suegra o ella misma quien asista su parto. Al acercarse el nacimiento la mujer se "hinca" frente a su marido que permanece sentado y pasa sus brazos alrededor de su cuello, en esta postura nacerá la criatura. La mujer indigena no muestra sus genitales, permanece totalmente vestida.

Al exponer que nosotros exploramos los genitales con la finalidad, entre otras, de reparar los desgarros que se pudieron producir, nos comentan que "las mujeres no son trapos y por eso no se costuran". Los desgarros casi no se producen y se curan a base de plantas medicinales y baños en el temazcal

Una situación que se considera de riesgo es el parto prolongado, porque puede ser que el niño tenga su "espíritu atrapado" debido a una mala conducta del esposo. Las parteras tienen sus remedios, como la utilización de infusiones y "secretos" para acelerar el parto, entre ellos, el rezo cumple un importante papel. Una de las consecuencia perniciosas de su contacto con la medicina alopática, es que algunas han comenzado a utilizar la oxitocina, poniendo en riesgo a la madre y al recién nacido.

La hemorragia durante el parto o alumbramiento se identifica como mortal y actualmente, aunque se sigue utilizando remedios tradicionales, se traslada a la mujer al hospital si así lo deciden los varones del grupo.

\section{Alumbramiento}

Se espera que la placenta salga rápido y no se cortará el cordón umbilical hasta después de ser expulsada ya que, si el bebé tuviera dificultades para respirar, comentan que, "poniendo la placenta en agua caliente, el bebé coge calor y respira".

La retención de placenta se trata con infusiones de hierbas, o ingiriendo un huevo duro, o provocando una fuerte contracción al inducir el vómito poniendo el pelo de la coleta de la mujer en su boca, - masajeando enérgicamente la matriz. Cuando 
estos métodos fallan, cortan el cordón umbilical y lo atan a un elote para evitar su sangrado e impedir que se retraiga al interior del útero (3), se espera a que salga o se traslada a la mujer al hospital.

El entierro de la placenta lo realizará el marido o en su ausencia, la partera. Puede hacerse dentro o fuera de la casa, dependiendo de si es niño o niña (5). Se considera que si se entierra dentro, el niño tendrá menos tolerancia al frío (4). También hay otras creencia sobre la posición en que se debe enterrar; si se desea que el próximo hijo sea varón, se pondrá la cara materna hacia abajo y al contrario si se desea niña. La profundidad en la que se entierra, estará relacionada con el espaciamiento de los embarazos.

\section{Cuidados al recién nacido y corte del cordón umbilical}

Cuando nace el bebé se lava, seca y se le tapa, mientras se espera que salga la placenta, después, se le entregará a la madre para que mame. La partera puede realizar un masaje que está relacionado con la protección al espíritu del recién nacido.

Si el niño presentó una circular, es señal de mala suerte y posible muerte violenta en el futuro, esto puede ser neutralizado por la partera pegando al niño con la placenta. Una vez que ha salido la placenta y ya lavado el niño, lo visten sujetando bien sus brazos y piernas para que "cuando sea mayor, no sea tan travieso, sea buen hombre o mujer y no robe". Si el parto ha sido dificultoso y el bebé llora continuamente y no se agarra al pecho, se piensa que tiene "el cuerpo quebrado" y deberá ser tratado por una partera o j'ilol para reunir sus partes (3).

En el corte del cordón se considerará si es niño o niña. Al niño se le dejará siete dedos de largo ya que se espera que sea fuerte y trabajador, además, el pene será más largo. Si se deja un cordón corto, no tendrá fuerza y se cansará pronto. El cordón de la niña será algo más corto, pero no menos de cuatro dedos ya que así no se cansará durante el trabajo y tendrá mejores partos.

El cordón se corta con carrizo, hoja de maíz o machete; actualmente se ha introducido la cuchi1la. Las tijeras generalmente no se utilizan, ya que "le da dolor de corazón al niño" (6). Si se desea que el próximo hijo sea varón, se cortará con hacha y se comerá gallo; si se quiere niña, se comerá gallina (4).

El cordón caerá a los tres días y el padre o uno de los hermanos, lo subirá a un árbol bien alto. Esto tiene su "secreto": "así el niño no tendrá miedo a la altura ni a los conflictos de la vida".

\section{Cuidados a la madre}

Se considera que los tres días posteriores al parto son los más arriesgados para la madre. Durante este tiempo debe ser cuidada por su marido, no salir de casa y rezar; se piensa que el demonio anda al acecho y podía llevarse a la madre y al recién nacido. Igualmente, será acompañada cuando va ha hacer sus necesidades para tapar los restos de sangre, ya que son una señal que indicaría al diablo el lugar donde se encuentran madre e hijo.

Algunas parteras recomiendan el baño "con plantas calientes" en el temazcal después del parto, actividad que realizarán acompañadas bien del marido o de la partera. Otras dejan el baño para después del tercer día, fecha en que ya puede salir a trabajar a la milpa con el marido aunque, habitualmente, la partera aconseje un descanso más prolongado.

Dependiendo de la situación familiar de la puérpera, la partera se quedará a su cuidado durante los tres días, encargándose de los trabajos habituales de la casa.

\section{CONCLUSIONES}

Hemos presentado un recorrido general de las representaciones y prácticas de la región de los 
Altos respecto a la reproducción, pero sin profundizar en las raíces de la cosmovisión indígena global, donde encontraríamos la respuesta efectiva de muchas de estas prácticas. En México perviven actualmente, como hemos expuesto, costumbres y creencias alrededor del nacimiento que son herencia de siglos (6). Algunas de ellas, también han sido practicadas en nuestro país (7-8).

En todas las sociedades, el proceso reproductivo ha sido uno de los acontecimientos que más ha atraído al ser humano por los misterios que encierra (9) y se han creado un sistema cultural de conceptos, saberes y habilidades a su alrededor en el intento, bien de comprenderlo, como de controlarlo y este sistema, variará de una sociedad a otra. Según el nivel de desarrollo social, acogerá respuestas que van de lo sobrenatural a lo científico.

Señalamos aquellas prácticas o concepciones que son diferentes actualmente a las llevadas a cabo en nuestra sociedad y como datos de interés cultural. El resto de cuidados al parto normal, son muy similares a los que se realizan hoy en nuestro entorno cuando se trata de un parto no medicalizado. En las grandes ciudades, las mujeres mestizas realizan el parto como en nuestros hospitales.

No todas las parteras y familias siguen las mismas tradiciones, las costumbres se van abandonando y la relación con la medicina alopática está introduciendo otras nuevas. Muchas parteras están participando en cursos de capacitación que se imparten desde diferentes organismos, esto favorece la adquisición de nuevos saberes con lo que, práctica obstétrica empirica y práctica obstétrica alopática son utilizadas en el cuidado a la salud reproductiva y dependiendo de las necesidades que se planten y adaptándose a los recursos existentes en la comunidad.

\section{BIBLIOGRAFÍA}

1.- Freyermuth, G.: 1993. Médicos tradicionales y Médicos alópatas, un encuentro dificil en los Altos de Chiapas. CIESASSureste. Instituto Chiapaneco de Cultura. Chiapas. México.

2.- Robledo Hernández G. Saldaña Fernández, M.: 1994. Pueblos indigenas de México. Tzotziles y Tzeltales. Instituto Nacional Indigenista. México.

3.- Freyermuth, G.: Tesis Doctoral. Centro de Investigaciones y Estudios Superiores en Antropología Social. (Sin publicar) Chiapas. México.

4.- Freyermuth,G. Cadena,B. Ico, M.: 1989. Alención del parto y del recién nacido en parteras indigenas de la región de los Altos de Chiapas. Cuadernos mujeres en solidaridad, $n^{\circ} 1$, Serie Nuestra salud. Chiapas. México.

5.- Lolez Auatin, A.: 1999. Un dia en la vida de una partera mexicana. Conaculta. México.

6.- Tibón Gutierre: 1992 La triade prenatal. Cordón, placenta y amnios. Supervivencia de la magia paleolítica. FCE. México.

7.- De Hoyos Sainz, L. (1942). "Folklore del embarazo en España". Anales de la Asociación Española para el Progreso. Vol. 7: 821-827.

8.- Salinas, R. (1905). La fascinación en España (Brujas, brujerias, amuletos). Madrid. Eduardo Arias.

9.- Mellado,V. Zolla, C. Castaneda, X.: 1989. La atención al embarazo y el parto en el medio rural mexicano. CIESS. México.

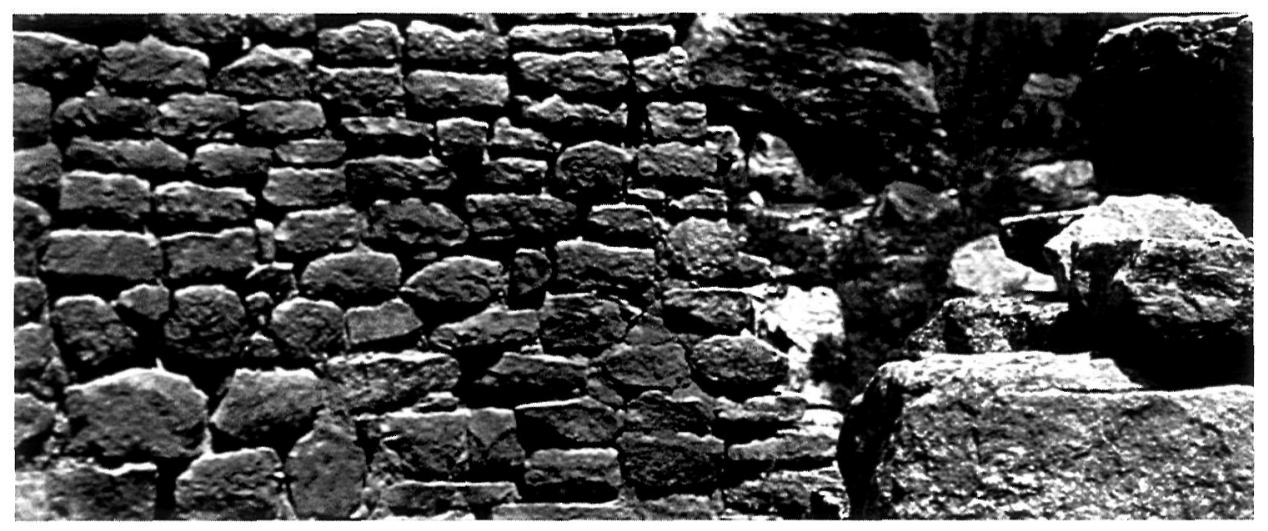

